\section{Stem cell populations in the heart and the role of Isl1 positive cells}

\author{
V. Di Felice, G. Zummo \\ Department of Experimental Biomedicine \\ and Clinical Neurosciences, University of \\ Palermo, Italy
}

\section{Abstract}

Cardiac progenitor cells are multipotent stem cells isolated from both embryonic and adult hearts in several species and are able to differentiate at least into smooth muscle cells, endothelial cells and cardiomyocytes. The embryonic origin of these cells has not yet been demonstrated, but it has been suggested that these cells may derive from the first and secondary heart fields and from the neural crest. In the last decade, two different populations of cardiac progenitor or stem cells have been identified and isolated, i.e., the Isletl positive (Isl1+) and c-Kit positive (cKit+)/Stem Cell Antigen-1 positive (Sca-1+) cells. Until 2012, these two populations have been considered two separate entities with different roles and a different origin, but new evidence now suggests a connection between the two populations and that the two populations may represent two subpopulations of a unique pool of cardiac stem cells, derived from a common immature primitive cell. To find a common consensus on this concept is very important in furthering the application of stem cells to cardiac tissue engineering.

\section{Islet1 positive cells during heart development}

At the end of 2003, the research group of Prof. Evans, using a mouse mutant for the LIM homeodomain transcription factor (Islet1, Isl1), demonstrated that an Isl1 positive (Isl1+) population is localised in the secondary heart field (SHF), contributing to the outflow tract, right ventricle, atria and (to a small extent) the left ventricle. ${ }^{1}$ Isl1 is considered a marker of SHF cells that contribute to the venous and arterial poles of the cardiac tube, while the other cells from the SHF contribute only to the arterial pole. ${ }^{2}$ The SHF or anterior heat field (AHF) was identified as a splanchnic mesoderm underlying the caudal pharynx, which provides myocardium to the outflow tract during tube looping. ${ }^{3,4}$ In 2005 , the same research group also identified Isll+/c-Kit negative (c-Kit-)/Stem Cell Antigen-1 negative (Sca-1-) progenitors in the post-natal heart, demonstrating that these cells persist after birth and that these organ-specific progenitor cells may be isolated, purified, expanded and differentiated into mature cardiac myocytes for future cardiac applications.

Our research group identified Isl1+ cells during gestation until the postnatal age, and demonstrated the contemporary expression of Isll and c-Kit in the interstitial cells in the ventricular myocardium in human foetal and postnatal hearts. This paper demonstrated, by confocal analysis, that all Isl1+ cells were also c-Kit+, while c-Kit+ cells were not necessarily Isl1+, as if Isl1+ cells were a subpopulation of c-Kit+ cells. ${ }^{5}$

It has been supposed that there may be a primordial cardiovascular precursor in the SHF that expresses the three markers Isl1, Nkx2.5 and Fetal Liver Kinase 1 (flkl) and can generate three lineages: cardiac muscle, smooth muscle and endothelium. ${ }^{6}$ The SHF cooperates with the first heart field (FHF) and the cardiac neural crest cells during the development of the vertebrate heart. ${ }^{7}$ The FHF lineage forms the early cardiac tube and generates the left ventricle, while the SHF contributes additional cells to the maturing heart and, along with the cardiac neural crest cells, generates the outflow tract vessels and valves. ${ }^{8}$

The presence of cardiovascular progenitor cells positive for Isll and/or Nkx2.5 in the SHF has been well confirmed by a recent work published in Science. ${ }^{9}$ The authors suggested that there are two distinct populations, one for the SHF and the other for the FHF; the first population is clearly positive for Isll and expresses miRNA 199a/b, while the second has no distinct markers and expresses miRNA $200 \mathrm{a} / \mathrm{b}$. Progenitor cells of the SHF depend on the cardiac specific transcription factors Isl1 and $\mathrm{Nkx} 2.5$, which play a key role at an early stage of cardiac progenitor formation. Their expression is regulated by Wnt/beta-catenin signalling, which in turn also regulates Bmp4 signalling. ${ }^{10}$ This last signalling pathway activates Gata4 and SRF.8 ${ }^{8}$ Despite the key role of Isl1, this transcription factor is not considered an indubitable marker of this subpopulation of SHF progenitor cells. It has been demonstrated very recently that Isl1 labels both SHF precursors and some cardiac neural crest cells and that Mef2C is a more efficient marker of the SHF progenitor cells in labelling experiments. ${ }^{11}$ This paper indirectly suggests both a review of past literature in view of these new data and using a different marker in studies of the SHF progenitor cells. Moreover, considering heart development in different species, such as chicken, mouse and Xenopus, it appears that Isll is expressed in a common cardiac cell population that splits into FHF and
Correspondence: Dr. Valentina Di Felice, Human Anatomy Section, Department of Experimental Biomedicine and Clinical Neurosciences, University of Palermo, 90127 Palermo, Italy. Tel. +39.09 .28378584 - Fax. +39.09 .16553580 . E-mail:vdfelice@inwind.it

Key words: cardiac progenitor cells, stem-cells, heart, lineages, biology, muscle.

Contribution: the authors have contributed equally to the paper.

Conflict of interests: the authors declare no potential conflict of interest.

Received for publication: 12 October 2012.

Accepted for publication: 8 February 2012.

This work is licensed under a Creative Commons Attribution NonCommercial 3.0 License (CC BYNC 3.0).

(C) Copyright V. Di Felice and G. Zummo, 2013 Licensee PAGEPress, Italy

European Journal of Histochemistry 2013; 57:e14 doi:10.4081/ejh.2013.e14

SHF lineages during heart development and that this common progenitor also contributes cells to the cardiovascular system. ${ }^{2}$

\section{Isl1 positive cells in the adult heart}

Since September 2003, when Prof. Anversa's research group described rat cardiac stem cells for the first time ${ }^{13}$ many research groups have claimed to have discovered new and important cardiac progenitor/stem cells in the adult heart. ${ }^{14}$ Since 2005 , the scientific community talked about adult c-Kit+ and/or Sca-1+ and/or MDR-1+ cells, and embryonic Isl1+ cells. These two populations have always been considered different entities and are described separately in many research papers and reviews, ${ }^{15-17}$ although expression of the Isl1 transcription factor by cardiac precursor cells has also been reported in adult hearts.

Our research group, in the same time as the research group of Prof. Di Nardo, described for the first time the concomitant expression of the three markers, i.e., c-Kit, Sca-1 and Isl1, in the same cardiac precursor cell. Prof. Di Nardo's research group described the concomitant expression of the Isll, c-Kit and Sca-1 markers in adult mouse cardiac progenitor cells in $2008,{ }^{18}$ while in 2009 our research group confirmed the expression of the three markers in adult rat CPCs. ${ }^{19}$ In a systematic work published in 2011 about the identifica- 
tion of Isl1+ cells in the mouse heart from postnatal day 1 to young adulthood in different strains, the authors found clusters of positive cells in the cardiac ganglia of the studied strains, while found very a few clusters of Isll+ cardiac precursors only in $129 \mathrm{SvJ}$ or Balb/C strains and in animals not older than 4 months. ${ }^{20}$

Recently Genead et al. ${ }^{21}$ demonstrated the contemporary expression of c-Kit and Isll markers in rat adult hearts in normal, pregnant and infarcted individuals. They reported the expression of both markers in the entire heart and in the right ventricle, the left ventricle, the outflow tract and the peri-infarct and peri-ischemia regions. Unfortunately, the study was based on real-time PCR analysis, and whenever immunocytochemistry was shown, no double staining for both markers had been performed. Other evidence supports the hypothesis that Isl1+ cells are not a different population from Sca-1+ CPCs. The contemporary expression of Sca-1 and Isl1 has been described both in a subpopulation of Sca$1+/ c$-Kit- cells identified and isolated from adult mouse hearts ${ }^{22}$ and in Sca-1+ cardiosphere-derived cells obtained from cardiac explants from normal, sham-operated or postmyocardial infarct hearts. ${ }^{23}$ In this study, only Sca-1+/CD45- cells were also positive for Isl1 and increased in number only after an acute myocardial infarct. ${ }^{23}$

Considering that other authors identified Isl1+ cells in adult murine and rat hearts, Weinberger et al. ${ }^{24}$ used heterozygous IsllLacZ mice, a more sensitive genetic approach, to investigate the presence and localisation of these precursor cells in 30 animals at different time points after birth (10 weeks to 18 months).

They found four different populations of Isl1+ cells: i) clusters of Isl1+ neurons were found in the cardiac parasympathetic ganglia of the posterior side of the heart and in the nervous plexus surrounding the pulmonary veins; ii) clusters of Isl1+ smooth muscle cells were found in the muscular layer above the aortic and pulmonary valve in the proximal part of the aorta and the trunk of the pulmonary artery (only a few positive cells were present in the aortic valve leaflets); iii) clusters of Isl1+ cardiomyocytes were found in the left ventricular outflow tract region; iv) clusters of Isl1+ sinoatrial node (SAN) cells were found in the muscular wall between right atrium and vena cava superior.

These results support the hypothesis that in the adult heart many cell populations may derive from Isl1+ embryonic precursors, as smooth muscle cells, parasympathetic neurons, SAN cells, but also that, even if reduced in number Isl1+ cardiomyogenic progenitors, may be present in the adult myocardium.

\section{Concluding remarks}

Many papers have been published on CPCs, and many research groups claimed to have discovered different populations of progenitor cells. It is strange to think that the cardiac tissue possesses a large number of stem/progenitor cells compared to the other tissues found in our body, and it is hopeful that CPCs may vary in number with external stimuli or with age as it happens for other adult stem cells. ${ }^{25,26}$ The hypothesis that the myocardium is a non-regenerative tissue is not valid any more, and much evidence supports the new idea that there is at least one cardiac progenitor cell.

Isl1+ and c-Kit+/Sca-1+ cells were considered to be two different populations until 2012, when Prof. Sussmann, citing our recent paper published in the European Journal of Histochemistry ${ }^{5}$ in an editorial in Circulation Research, suggested considering the possibility of studying a population of cells positive for both Isl1 and c-Kit instead of choosing to study only one side of the coin. ${ }^{27}$ In the review ${ }^{14}$ and in the research paper ${ }^{19}$ published in 2009 , we reported the concomitant expression of Isl1, cKit and Sca-1 in a population of CPCs isolated without any sorting or selection and suggested for the first time that there could be a unique population of cells with several subpopulations and that the several markers identified could be only the effect of different cultivation conditions in the different laboratories. Other research groups later described the co-expression of Isl1, Sca-1 and/or c-Kit ${ }^{21,22}$ and we further demonstrated that, in samples from foetal and postnatal human hearts, there was also an Isl1+ subpopulation of c-Kit+ cells. ${ }^{5}$

Finally, in January 2012 a paper was published, with Prof. Anversa among the authors, on a study of the presence of c-Kit+ cardiac stem cells in embryonic, foetal and neonatal mouse hearts. ${ }^{28}$ They demonstrated that these cells can form cardiomyocytes and coronary vessels and, as we have demonstrated in our paper, they are more abundant than Isl1+ cells. Moreover, they stated that Isl1+ cells are present only in the outflow tract, atria and part of the right ventricle and that they are a population of committed cells derived from an immature primitive cell.

We can say that there is strong evidence suggesting that c-Kit, Sca-1 and Isll may be markers of subpopulations of CPCs that are present in the embryonic, foetal and neonatal heart and persist from after birth until adulthood. The identification of the real immature cardiac precursor expressing the four cell markers (c-Kit, Sca-1, MDR-1 and Isl1) and above all the identification of a unique isolation protocol is very important in the clinical practice. This immature common car- diac precursor may represent the perfect candidate for cardiac tissue engineering and, hopefully, may be driven pharmacologically to one phenotype or the other. To identify a standardised protocol is extremely important to go further in the studies on cardiac tissue regeneration, and common guidelines are needed in cardiac stem cell therapy. The isolation of stem cells by cell sorting or immunobead selection using surface markers such as c-Kit, Sca1 or MDR-1 is important to identify a standardised protocol of isolation, however Isll may be useful in basic research to follow the fate of CPCs in heart development and myocardium differentiation.

Moreover, it is extremely important to understand which is the predominant precursor population in the different stages of life and which population should be used in a paediatric patient instead of an adult one. If fate of immature cardiac precursors may be determined pharmacologically, the possibility to regenerate SAN cells is very important in curing arrhythmia's both in patients with ischemia and malformations.

The identification of the different subpopulations in the developing heart may be a fundamental step in identifying the optimal cell line for cell-based therapies.

\section{References}

1. Cai CL, Liang X, Shi Y, Chu PH, Pfaff SL, Chen J, et al. Isll identifies a cardiac progenitor population that proliferates prior to differentiation and contributes a majority of cells to the heart. Dev Cell 2003;5:877-89.

2. Buckingham M, Meilhac S, Zaffran S. Building the mammalian heart from two sources of myocardial cells. Nat Rev Genet 2005;6:826-35.

3. Waldo KL, Kumiski DH, Wallis KT, Stadt HA, Hutson MR, Platt DH, et al. Conotruncal myocardium arises from a secondary heart field. Development 2001;128:3179-88.

4. Mjaatvedt $\mathrm{CH}$, Nakaoka T, MorenoRodriguez R, Norris RA, Kern MJ, Eisenberg CA, et al. The outflow tract of the heart is recruited from a novel heartforming field. Dev Biol 2001;238:97-109.

5. Serradifalco C, Catanese P, Rizzuto L, Cappello F, Puleio R, Barresi V, et al Embryonic and foetal Islet-1 positive cells in human hearts are also positive to c-Kit. Eur J Histochem 2011;55:e41.

6. Moretti A, Caron L, Nakano A, Lam JT, Bernshausen A, Chen Y, et al. Multipotent embryonic isll+ progenitor cells lead to cardiac, smooth muscle, and endothelial 
cell diversification. Cell 2006;127:1151-65.

7. Di Felice V, Zummo G. Tetralogy of fallot as a model to study cardiac progenitor cell migration and differentiation during heart development. Trends Cardiovasc Med 2009;19:130-5.

8. Klaus A, Muller M, Schulz H, Saga Y, Martin JF, Birchmeier W. Wnt/beta-catenin and Bmp signals control distinct sets of transcription factors in cardiac progenitor cells. Proc Natl Acad Sci USA 2012;109: 10921-6.

9. Domian IJ, Chiravuri M, van der Meer P, Feinberg AW, Shi X, Shao Y, et al. Generation of functional ventricular heart muscle from mouse ventricular progenitor cells. Science 2009;326:426-9.

10. Santoro A, Pannone G, Errico ME, Bifano D, Lastilla G, Bufo P, et al. Role of -catenin expression in paediatric mesenchymal lesions: a tissue microarray-based immunohistochemical study. Eur J Histochem 2012;56:e25.

11. Engleka KA, Manderfield LJ, Brust RD, Li L, Cohen A, Dymecki SM, et al. Islet1 derivatives in the heart are of both neural crest and second heart field origin. Circ Res. 2012;110:922-6.

12. Pandur P, Sirbu I0, Kuhl SJ, Philipp M, Kuhl M. Islet1-expressing cardiac progenitor cells: a comparison across species. Dev Genes Evol 2013;223:117-29.

13. Beltrami AP, Barlucchi L, Torella D, Baker M, Limana F, Chimenti S, et al. Adult cardiac stem cells are multipotent and support myocardial regeneration. Cell 2003;114:763-76.

14. Di Felice V, De Luca A, Colorito ML, Montalbano A, Ardizzone NM, Macaluso F, et al. Cardiac stem cell research: an elephant in the room? Anat Rec (Hoboken) 2009;292:449-54.

15. Moretti A, Lam J, Evans SM, Laugwitz KL. Biology of Isl1+ cardiac progenitor cells in development and disease. Cell Mol Life Sci 2007;64:674-82.

16. Torella D, Ellison GM, Karakikes I, NadalGinard B. Cardiovascular development: towards biomedical applicability : Resident cardiac stem cells. Cell Mol Life Sci 2007;64:661-73.

17. Di Meglio F, Nurzynska D, Castaldo C, Arcucci A, De Santo L, de Feo M, et al. In vitro cultured progenitors and precursors of cardiac cell lineages from human normal and post-ischemic hearts. Eur J Histochem 2007;51:275-82.

18. Forte G, Carotenuto F, Pagliari F, Pagliari S, Cossa P, Fiaccavento R, et al. Criticality of the biological and physical stimuli array inducing resident cardiac stem cell determination. Stem Cells 2008;26:2093-103.

19. Di Felice V, Ardizzone NM, De Luca A, Marciano V, Gammazza AM, Macaluso F, et al. OPLA scaffold, collagen I, and horse serum induce an higher degree of myogenic differentiation of adult rat cardiac stem cells. J Cell Physiol 2009;221:729-39.

20. Khattar P, Friedrich FW, Bonne G, Carrier L, Eschenhagen T, Evans SM, et al. Distinction between two populations of islet-1-positive cells in hearts of different murine strains. Stem Cells Dev 2011;20:1043-52.

21. Genead R, Fischer H, Hussain A, Jaksch M, Andersson $\mathrm{AB}$, Ljung $\mathrm{K}$, et al. Ischemiareperfusion injury and pregnancy initiate time-dependent and robust signs of up- regulation of cardiac progenitor cells. PLoS One 2012;7:e36804.

22. Takamiya M, Haider KH, Ashraf M. Identification and characterization of a novel multipotent sub-population of Sca$1(+)$ cardiac progenitor cells for myocardial regeneration. PLoS One 2011;6: e25265.

23. Ye J, Boyle A, Shih H, Sievers RE, Zhang Y, Prasad M, et al. Sca-1+ cardiosphere-derived cells are enriched for Isl1-expressing cardiac precursors and improve cardiac function after myocardial injury. PLoS One 2012;7:e30329.

24. Weinberger F, Mehrkens D, Friedrich FW, Stubbendorff M, Hua X, Muller JC, et al. Localization of Islet-1-positive cells in the healthy and infarcted adult murine heart. Circ Res 2012;110:1303-10.

25. Macaluso F, Brooks NE, van de Vyver M, Van Tubbergh K, Niesler CU, Myburgh KH. Satellite cell count, VO(2max), and p38 MAPK in inactive to moderately active young men. Scand J Med Sci Sports 2012; 22:e38-44.

26. Macaluso F, Myburgh KH. Current evidence that exercise can increase the number of adult stem cells. J Muscle Res Cell Motil 2012;33:187-98.

27. Sussman MA. Myocardial Isl(+)land: a place with lots of rhythm, but no beat. Circ Res 2012 11;110:1267-9.

28. Ferreira-Martins J, Ogorek B, Cappetta D, Matsuda A, Signore S, D’Amario D, et al. Cardiomyogenesis in the developing heart is regulated by c-kit-positive cardiac stem cells. Circ Res 2012;110:701-15. 